\title{
A Decision-Making Approach for Supplier Selection in the Presence of Supply Risk
}

\author{
Z. Khojasteh-Ghamari and T. Irohara \\ Faculty of Science and Technology, Sophia University, Tokyo, Japan \\ Email: khojaste.z@gmail.com; Irohara@sophia.ac.jp
}

Received 15 August 2017; Accepted 26 December 2017;
Publication 17 January 2018

\begin{abstract}
In order to deal with the various kind of risks in a supply chain, we need to have different approaches. In this study, we propose a mathematical programming model to manage the supply risk considering multi layer feature of the supply chain. The aim of this model is managing the supply chain risk by controlling the selection of suppliers. By having this approach, we aim to lower the risk of supplier disruption. We examine various datasets to observe the behaviour of the proposed model in different data sizes through the several steps. Analysing the results of different datasets, we show the trend of objective value by increasing data sizes. Besides, we analyse the increasing ratio of cost within different steps of the model. Finally, we discuss the effect of our proposed approach on the total cost.
\end{abstract}

Keywords: Supply chain risk, Mathematical programming model, Supplier selection, Multi sourcing.

\section{Introduction}

In today's global marketplace, firms are relying more on their supply chains to remain competitive [1]. In the past, supply chain managers mainly focused on reducing costs, and apparently, this was the only main objective of the studies; but recently, they have begun to give importance to supply chain

Journal of Industrial Engineering and Management Science, Vol. 1, 1-14. doi: 10.13052/jiems2446-1822.2018.001

This is an Open Access publication. (c) 2018 the Author(s). All rights reserved. 
continuity and resiliency which have significant impacts on costs as well. Hence, conventional reactive planning has given way to proactive planning in Supply Chain Risk Management (SCRM) [2]. Proactive planning is preparing to avoid risky situations before disruption happens. However, a reactive approach is the response to the disruption outcomes, after it occurs.

In the literature, there are many studies to mitigate the supply chain risk [3]. [4] summarized the mitigation strategies in SCRM. In order to mitigate the negative consequences of supply disruptions, many companies apply the strategy of sourcing from two or more suppliers; a strategy called dual or multiple sourcing [5]. Talking about single sourcing versus multi sourcing, we have to deal with the trade-off between cost and risk. Single sourcing is a powerful approach in a stable environment. However, it can amplify a firm's exposure to risk in the presence of uncertainty. On the other hand, in realistic situations that we deal with the risk and uncertainty in SC, multiple sourcing can ensure the resilience of the Supply Chain (SC). However, due to the management of more than one supplier, it involves higher costs [6]. Following the concept of multiple sourcing, backup supplier selection is referred to the decisions that are made before any disruption happens. Multi sourcing decisions, however, must be made to respond to disruptions after they happen within the supply chain. A backup supplier is a secondary supplier that is used in the case that the primary supplier is disrupted. Backup supplier ensures that the flow of material is maintained in case of disruption in other sources. In compared to a multi-sourcing strategy, in which all suppliers are used as primary sources of materials, backup suppliers are only used when primary suppliers are unavailable [7]. In this study, our approach is based on multi sourcing, therefore, our approach is a proactive approach in SCRM. The researchers developed two linear programming models to maximize and minimize the performance of a supplier against the best target measures set by the buyer. Measuring both maximum and minimum efficiencies of each supplier would achieve a comprehensive understanding of a supplier performance [8]. [9] presented a mixed-integer linear programming model for the supplier selection problem. The model decision variable was determining the optimal number of suppliers, and the optimal order quantity with the objective of maximizing the total revenue. [6] proposed the Real Options approach for valuing the probabilistic benefits of multiple sourcing in managing the supplier default risk. They presented the trade-off between single and multiple sourcing depending on deterministic and probabilistic factors in risky environments. The results of their proposed model showed the probabilistic advantages of adopting the multiple sourcing strategy in 
risky environments for a specific case. [7] assessed the effectiveness of incorporating three types of redundancy practices (pre-positioning inventory, backup suppliers, and protected suppliers) into a firm's supply chain exposing supply risk and environmental risk. Multi-sourcing was their only supplier strategy shared in all the practices. [10] studied a manufacturer's single versus multiple sourcing decision under specific consideration of the effects on the evolution of power between the buyer and its supply base. Considering this trade-off, they found that the buyer's optimal sourcing strategy depends on both its bargaining capabilities and the rate at which learning by doing reduces production costs. In [11] they studied the problem of supplier selection and customer order scheduling for single and multiple sourcing strategies considering disruption risks. He considered supplier, regional and global disruption and developed a MIP model with conditional value at risk as a risk measure, with the objective of either minimizing expected worst case loss or maximizing expected worst case service level. Comparing the risk-averse solutions for two sourcing strategies, he reported managerial insights on the choice between the two strategies. He concluded that a multiple sourcing strategy better mitigates the risk of high costs or low service levels. This finding is in line with other papers in the area of SCRM. Later [12] developed a mixed-integer model for the previous model [11] to obtain a robust solution. Their study showed that the service level and the cost objective functions are in conflict. The best service-level based solutions may perform poorly with respect to the cost-based metrics and vice versa. [13] combined two factors of supply disruption and loss-aversion by considering a loss-averse firm facing a random demand and sourcing from two suppliers. One supplier considered cheaper but subject to potential disruption possibility, while the other one was reliable but more expensive to purchase from. He found that the unreliable supplier is the main supplier whose order quantity is always positive despite its unreliability attribute, while the reliable supplier can never be used when its purchase cost or the reliability of its opponent is too high. They also found that the unreliable supplier is always used with positive order quantity due to its economic advantage, while the reliable supplier can be useless under some condition. [14] considered a two-level supply chain consisting of a manufacturer and three suppliers under supply disruption from an unreliable supplier. They found that in case of working with two reliable suppliers along with unreliable supplier, disruption probability has no significant effect on optimal selling prices of reliable suppliers when manufacturer is leader in market. Also, disruption probability has significant effect on profit of manufacturer and suppliers and also manufacturer's orders. [15] presented an 
analytical approach to investigate trade-offs in integrated supplier selection and inventory decision problems. In their study, since they considered the warehouses replenish their inventory via multiple suppliers, their problem was a multi-sourcing, supplier selection. [16] studied the effect of dual sourcing strategy on risk reduction in cases where both suppliers are prone to disruption. They mentioned that saving resulted from dual sourcing strategy is considerable if demand is distributed optimally between two sources. Disruption can happen in every tier of SC. In order to design a SC network which is resilient for risks and disruptions, we need to control every point of the SC. If any disruption occurs in suppliers, the manufacturer will not be able to produce the final product. Similarly, if the suppliers do not receive parts from sub suppliers, they can not provide and deliver to the manufacturer. Therefore, any disruption in one of the sub-suppliers will directly affect the entire SC. In this study, one of the important elements in designing our model is sup suppliers. The paper is organized as follow. Section 2, defines the parameters, indexes and the model structure. In Section 3, we examine the proposed model by different datasets and analyze the results. Finally, Section 4 concludes the paper.

\section{Problem Statement}

In this model, we propose an optimization approach to manage the Supply Chain Risk (SCR). The objective of this model is minimizing the total cost including purchasing cost and initial contract cost.

The problem is based on the selection from many suppliers for many manufacturers. Each candidate supplier has different purchasing cost. Moreover, we add more criterion to the supplier selection. We avoid selection of suppliers which have the same sub-suppliers. This strategy is controlling the disruptions in the lower tier supply chain. Figure 1 illustrates a simple view from the relationship between manufacturers, suppliers and sub-suppliers. As shown in Figure 1, supplier 1 and supplier 2 can not be selected together in our model. The reason is that they are sharing the same sub-supplier (subsupplier 2). Similarly, suppliers 2 and 3 can not be selected together, since they have a shared sub-supplier which in this case it is sub-supplier 3 . The purpose of considering these criteria is the cases that a sub-supplier is disrupted. Then, all the suppliers which get parts from that particular sub-supplier will be affected as they can not receive supplies from that disrupted sub-supplier. As a consequence, they all will have the same problem and can not deliever the 


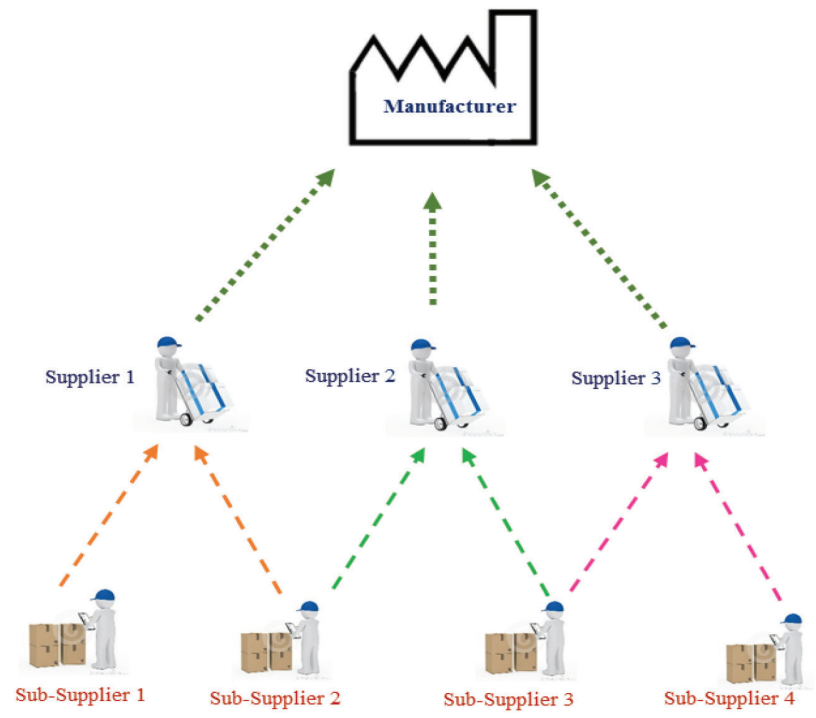

Figure 1 Relation between manufacturer, suppliers and, sub-suppliers.

parts to the above tier. Our idea is avoiding the selection of supplier which are getting parts from the same sub-suppliers to prevent this problem.

In this study, we propose an extended approach to double sourcing. The purpose is to control supplier selection by considering their lower tier suppliers.

The following notations are defined for formulating our proposed model:

Indexes:

$i \quad$ index of suppliers

$j \quad$ index of manufacturers

$q \quad$ index of sub-suppliers

Parameters:

$p_{i} \quad$ Unit purchasing cost of supplier $i$

$h_{i} \quad$ Initial contract cost with supplier $i$

$c_{i} \quad$ Capacity of supplier $i$

$d_{j} \quad$ Demand of manufacturer $j$

$M \quad$ Big number

$s_{i q}:\{=1$, if $q$ is the sub-supplier of supplier $i$,

$k \quad$ minimum order from each supplier 
Decision variables:

$y_{i j} \quad$ Quantity to be transferred from supplier $i$ to manufacturer $j$

$a_{i j}:\left\{\begin{array}{l}=1, \text { if supplier } i \text { is selected for manufacturer } j, \\ =0, \text { Otherwise; }\end{array}\right.$

$$
\text { Minimizing Cost } \sum_{i \in I} \sum_{j \in J} p_{i} * y_{i j}+\sum_{i \in I} \sum_{j \in J} h_{i} * a_{i j}
$$

subject to

$$
\begin{array}{lr}
y_{i j} \geq 0 & \forall i \in I, \forall j \in J \\
\sum_{j} y_{i j} \leq c_{i} & \forall i \in I \\
\sum_{i} y_{i j} \geq d_{j} & \forall j \in J \\
\sum_{i} a_{i j} \geq 2 & \forall j \in J \\
\sum_{i} a_{i j} * s_{i q} \leq 1 & \forall j \in J, \forall q \in Q \\
y_{i j} \geq k * a_{i j} & \forall i \in I, \forall j \in J \\
y_{i j} \geq a_{i j} & \forall i \in I, \forall j \in J \\
y_{i j} \leq M * a_{i j} & \forall i \in I, \forall j \in J
\end{array}
$$

Equation (1) is the only objective function in our proposed model, it is minimizing the total cost; which includes initial contract cost with each supplier and unit purchasing cost of each supplier. We consider a primary contract cost for each supplier. This parameter will be considered only once, regardless of the amount of orders from the supplier. Constraint (2) is applying the non-negativity feature of the decision variable. Constraint (3) serves as the capacity constraint for each supplier. This constraint is for the cases that due to the low cost of a supplier, there are too many requests from it. By considering the capacity of each supplier, we limit the number of requests from it. Constraint (4) specifies that for each manufacturer, the total number of supplies to be received should be equal or more than its demand. In the other words, this constraint indicates the necessity of demand satisfaction. In this model, since the objective function is minimizing the total cost, the number of requested items from suppliers will be exactly equal to the demand of manufacturers and not more. Constraint (5) specifies that the number of selected suppliers for each manufacturer should be equal or more than two. 
This constraint is representing the concept of double sourcing. It means that for each manufacturer at least two suppliers should be selected. In this case, if one of the suppliers will be disrupted, at least there is the other one which can provide the supplies and therefore, the disruption in entire $\mathrm{SC}$ will not happen. Constraint (6) prevents the selection of the suppliers which have the same subsuppliers. So, our SCRM model controls suppliers according to the second tier suppliers. This is beneficial for the case that a sub-supplier is disrupted and if both suppliers of our model receive their primary materials from that subsupplier, then both the suppliers will confront disruption and eventually all the SC network will face supply problem. Constraint (7) specifies the minimum number of order from each supplier which makes the model more realistic. If we relax this constraint, then the result would be only a single unit of order. Finally, Constraints (8) and (9) define the relationship between binary and integer decision variables.

\section{Numerical Examples}

In this section, in order to show the validity of the above-mentioned optimization approach, we tested several datasets. We solve the model using Gurobi Optimizer Version 6.5.0 mathematical programming solution software. All experiments were run on a personal computer with an Intel (R) Core (TM) i7-6700 CPU (3.40 GHz) and 16.0 GB of RAM. All the runs solved in about 1 second.

\subsection{Experimental Results}

In this section, as sample, we selected 10 datasets which their information is shown in Table 1. These datasets were different in terms of their size. The size of datasets is randomly generated. Dataset number 1 has only 3 candidate suppliers, 1 manufacturer, and 4 sub-suppliers. Dataset number 2 is slightly bigger than dataset number 1 , with 5 candidate suppliers and 6 sub-suppliers. From dataset number 3 to number 10, number of suppliers and sub-suppliers increase. The unit purchasing cost of suppliers and the initial contract cost assigned randomly between the span of 93 and 105 by keeping the average cost the same in all the datasets. Table 2 shows the results after running the program. Changing the size of datasets did not have any effect on the time of running the program. In all these datasets, we could see the optimal results in about one second. The results are the selection of two suppliers for each manufacturer. We set the demand of manufacturer to 100 . As the model is double sourcing, 
Table 1 Information of parameters in 10 datasets

\begin{tabular}{llll}
\hline Dataset & $\begin{array}{l}\text { Number of } \\
\text { Suppliers }\end{array}$ & $\begin{array}{l}\text { Number of } \\
\text { Manufacturers }\end{array}$ & $\begin{array}{l}\text { Number of } \\
\text { Sub-suppliers }\end{array}$ \\
\hline 1 & 3 & 1 & 4 \\
2 & 5 & 1 & 6 \\
3 & 7 & 1 & 8 \\
4 & 9 & 2 & 11 \\
5 & 10 & 2 & 12 \\
6 & 12 & 2 & 13 \\
7 & 13 & 3 & 14 \\
8 & 14 & 3 & 15 \\
9 & 15 & 3 & 15 \\
10 & 17 & 3 & 18 \\
\hline
\end{tabular}

Table 2 Results of 10 datasets

\begin{tabular}{|c|c|c|c|c|c|c|c|}
\hline & $\begin{array}{l}\text { Purchasing } \\
\text { Price from } \\
\text { Primary }\end{array}$ & $\begin{array}{l}\mathrm{h}_{i} \text { of } \\
\text { Primary }\end{array}$ & $\begin{array}{l}\text { Number of } \\
\text { Orders } \\
\text { from } \\
\text { Primary }\end{array}$ & $\begin{array}{l}\text { Purchasing } \\
\text { Price from } \\
\text { Secondary }\end{array}$ & $\begin{array}{l}\mathrm{h}_{i} \text { of } \\
\text { Secondary }\end{array}$ & $\begin{array}{l}\text { Number } \\
\text { of Orders } \\
\text { from } \\
\text { Secondary }\end{array}$ & Total \\
\hline Dataset & Supplier & Supplier & Supplier & Supplier & Supplier & Supplier & Price \\
\hline 1 & 105 & 200 & 90 & 107 & 200 & 10 & 10920 \\
\hline 2 & 104 & 199 & 90 & 108 & 201 & 10 & 10840 \\
\hline 3 & 102 & 197 & 90 & 107 & 200 & 10 & 10647 \\
\hline 4 & 101 & 196 & 90 & 106 & 199 & 10 & 10545 \\
\hline 5 & 100 & 195 & 90 & 106 & 199 & 10 & 10454 \\
\hline 6 & 97 & 192 & 90 & 105 & 198 & 10 & 10170 \\
\hline 7 & 96 & 191 & 90 & 105 & 198 & 10 & 10079 \\
\hline 8 & 96 & 191 & 90 & 104 & 197 & 10 & 10068 \\
\hline 9 & 94 & 189 & 90 & 104 & 197 & 10 & 9886 \\
\hline 10 & 93 & 188 & 90 & 104 & 197 & 10 & 9795 \\
\hline
\end{tabular}

the result will be two selected suppliers for each manufacturer. We call the first selected supplier with the lowest cost as "primary" and the second lowest price supplier as "secondary". Assigning 90 over 100 of demand to primary supplier and the rest of 10 to the secondary supplier.

After running the program of the selected sample datasets, we had the minimum feasible objective value for each dataset. The objective value includes the total purchasing costs and the initial contract costs from the two suppliers. The observation from the selected datasets is presented in Table 1. Moreover, Figure 2 shows the results of the selected sample datasets which by adding the number of candidate suppliers, the amount of total cost either decreases or stays the same value. We can interpret this tendency as follows. 


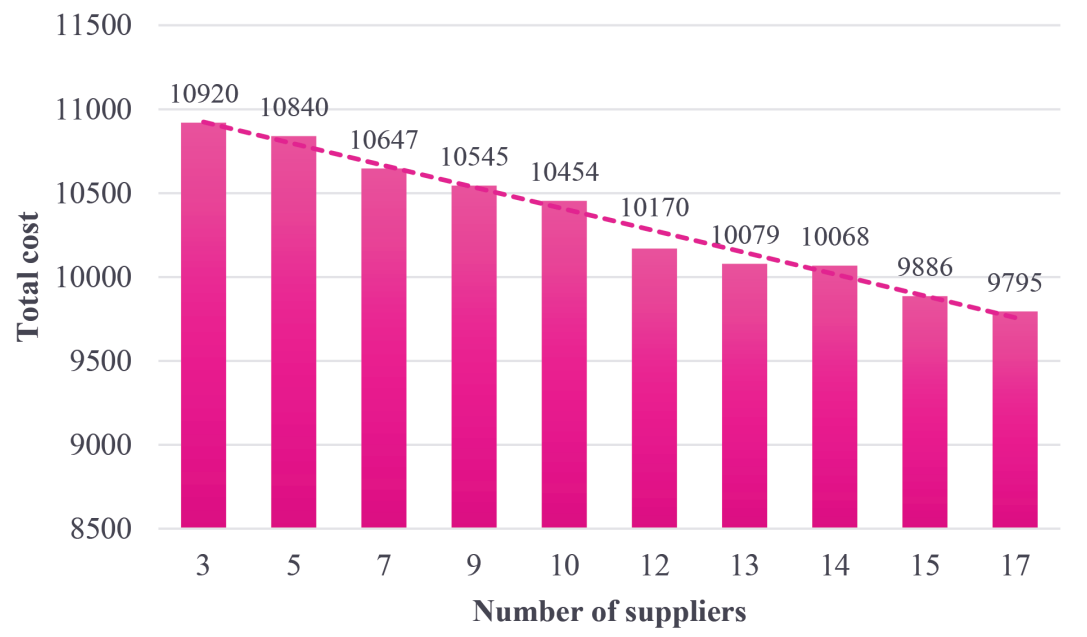

Figure 2 Total cost variation by adding suppliers.

As we know by adding the number of suppliers, the SC network will be bigger. Consequently, the supplier selection will be more flexible. Apparently, there is a direct relationship between the number of suppliers and number of sub suppliers. When there is a limited number of candidate suppliers, then the selection will be limited. Once the number of suppliers increases, number of sub suppliers grows as well. Knowing that supplier selection of this model is selecting two suppliers which are not sharing the same sub supplier. By adding the number of candidate suppliers, the number of sub suppliers increases as well. Therefore, the supplier selection in this model will be more flexible. Thus, the model will have more options to select with broad cost options, and finally, the total cost will be lower. As it is shown in Figure 2, in general, by increasing the number of candidate suppliers, the amount of total cost decreases.

\subsection{Cost Variation}

Moreover, we break down the model into three steps. Step one is adding double sourcing constraint (Constraint 5). Step two is adding constraint number 6 which assigns as the two selected suppliers should not share the same sub supplier. Our motivation to consider disruption in multi layer supply chain is a paper analysing Toyota industry's problem after tsunami occurred in 2011 [17]. This paper focuses on a case of supply disruption of the automotive microcontroller units supplied to Toyota via its first tier suppliers. As we 
Table 3 Cost variation within three steps of SCRM

\begin{tabular}{llllllll}
\hline & $\begin{array}{l}\text { Total Cost } \\
\text { Before }\end{array}$ & $\begin{array}{l}\text { Total Cost } \\
\text { After }\end{array}$ & $\begin{array}{l}\text { Total Cost } \\
\text { After }\end{array}$ & $\begin{array}{l}\text { Total Cost } \\
\text { After }\end{array}$ & $\begin{array}{l}\text { Increasing } \\
\text { Rate of }\end{array}$ & $\begin{array}{l}\text { Increasing } \\
\text { Rate of }\end{array}$ & $\begin{array}{l}\text { Increasing } \\
\text { Rate of } \\
\text { Dataset }\end{array}$ \\
Step 1 & Step 1 & Step 2 & Step 3 & Step 1 & Step 2 & Step 3 \\
\hline 1 & 10700 & 10902 & 10906 & 10920 & 0.0189 & 0.0004 & 0.0013 \\
2 & 10599 & 10804 & 10806 & 10840 & 0.0193 & 0.0002 & 0.0032 \\
3 & 10397 & 10602 & 10602 & 10647 & 0.0197 & 0.0000 & 0.0043 \\
4 & 10296 & 10500 & 10504 & 10545 & 0.0198 & 0.0004 & 0.0040 \\
5 & 10195 & 10400 & 10402 & 10454 & 0.0201 & 0.0002 & 0.0051 \\
6 & 9892 & 10098 & 10098 & 10170 & 0.0208 & 0.0000 & 0.0073 \\
7 & 9791 & 9998 & 10000 & 10079 & 0.0211 & 0.0002 & 0.0081 \\
8 & 9791 & 9996 & 9996 & 10068 & 0.0209 & 0.0000 & 0.0074 \\
9 & 9589 & 9796 & 9798 & 9886 & 0.0216 & 0.0002 & 0.0092 \\
10 & 9488 & 9696 & 9698 & 9795 & 0.0219 & 0.0002 & 0.0102 \\
\hline
\end{tabular}

know Toyota stopped production for sometimes after the big tsunami in 2011 in Japan, since some functions were missing in the supply chain coordination mechanism of Toyota Production System. It was because there was a close interaction between the successive layers of its multi-layered supplier network. This case analysis implied that not only the first tier suppliers but also their sub suppliers (second tier supplier) need to be controlled. The strategy to control the second tier supplier is applied in step 2 of the proposed model. Step three includes the constraint number 7, while parameter " $k$ " is set to 10 . The results of numerical examples show that the most percentage of increasing is in step 1, then in step 3 and the least is in step 2. Step 1 includes the major increasing, mostly because of the initial contract cost parameter $\left(\mathrm{h}_{i}\right)$. Table 3 shows the objective value of 10 datasets and its variation in three above-mentioned steps. Following the table, Figure 3 depicts the increasing ratio of the cost in three

\section{Cost increasing ratio in 3 steps}

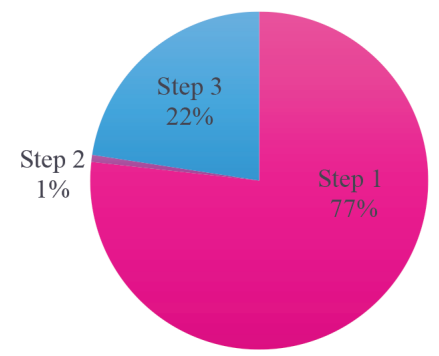

Figure 3 Increasing ration of the total cost while applying SCRM in 3 steps. 
steps following the same data in Table 3. As it is shown in Figure 3, the constraint that we considered for sub-suppliers (Constraint 6), has the least (Around 1\%) of affect in total increasing rate of cost.

\section{Conclusion}

In this paper, we proposed an optimization approach for managing supply chain risk. After reviewing the state of art in SCRM, we selected multiple sourcing strategy as one of the SCRM strategies. We applied double sourcing as the base of SCRM strategy in our model. Moreover, we avoided the risky situations when both suppliers have the single point for disruption. In the proposed model, we restricted the supplier selection by considering the risk in second tier suppliers. We examined the model by various datasets. We examined ten datasets with different data sizes. The results of the sample datasets showed the variation of total cost by adding candidate suppliers. Besides, we considered the model with three steps of implementation of SCRM methods and we noticed that the main increase in total cost occurs after the first step.

In our future work, we aim to add the demand risk of manufacturer to the current model. Moreover, by considering more criteria, we plan to design more robust SC. The proposed model can be extended to multi objective function by considering more important parameters and strategies of SCRM.

\section{References}

[1] Kamalahmadi, M., and Mellat-Parast, M. (2016). Developing a resilient supply chain through supplier flexibility and reliability assessment. Int. J. Production Res. 54, 302-321.

[2] Kirilmaz, O., and Erol, S. (2017). A proactive approach to supply chain risk management: Shifting orders among suppliers to mitigate the supply side risks. J. Purchasing and Supply Manage. 23, $54-65$.

[3] Khojasteh-Ghamari, Z. and Irohara, T. (2017). Supply Chain Risk Management: A Review, in Khojasteh, Y (ed.), Supply Chain Risk Management: Advanced Tools, Models, and Developments, Springer, 3-22.

[4] Ho, W., Zheng, T., Yildiz, H., and Talluri, S. (2015). Supply chain risk management: a literature review. Int. J. Production Res. 53, 5031-5069. 
[5] Tomlin, B., and Wang, Y. (2011). Operational strategies for managing supply chain disruption risk. The Handbook of Integrated Risk Management in Global Supply Chains, 79-101.

[6] Costantino, N., and Pellegrino, R. (2010). Choosing between single and multiple sourcing based on supplier default risk: A real options approach. J. Purchasing and Supply Management, 16, 27-40.

[7] Kamalahmadi, M., and Parast, M. M. (2017). An assessment of supply chain disruption mitigation strategies. Int. J. Production Economics, 184, 210-230.

[8] Ho, W., Xu, X., and Dey, P. K. (2010). Multi-criteria decision making approaches for supplier evaluation and selection: A literature review. Eur. J. Operational Res. 202, 16-24.

[9] Hong, G. H., Park, S. C., Jang, D. S., and Rho, H. M. (2005). An effective supplier selection method for constructing a competitive supply-relationship. Expert Systems with Applications, 28, 629-639.

[10] Heese, H. S. (2015). Single versus multiple sourcing and the evolution of bargaining positions. Omega, 54, 125-133.

[11] Sawik, T. (2014a). Optimization of cost and service level in the presence of supply chain disruption risks: Single vs. multiple sourcing. Comput. Operations Res. 51, 11-20.

[12] Sawik, T. (2014b). On the robust decision-making in a supply chain under disruption risks. Int. J. Production Res. 52, 6760-6781.

[13] Li, X., and Li, Y. (2016). On the loss-averse dual-sourcing problem under supply disruption. Comput. Operations Res. Available at: http://dx.doi.org/10.1016/j.cor.2016.12.011

[14] Mohammadzadeh, N., and Zegordi, S. H. (2016). Coordination in a triple sourcing supply chain using a cooperative mechanism under disruption. Comput. Ind. Eng. 101, 194-215.

[15] Firouz, M., Keskin, B. B., and Melouk, S. H. (2017). An integrated supplier selection and inventory problem with multisourcing and lateral transshipments. Omega, 70, 77-93. Available at: http://dx.doi.org/10.1016/j.omega.2016.09.003i

[16] Silbermayr, L., and Minner, S. (2016). Dual sourcing under disruption risk and cost improvement through learning. Eur. J. Operational Res. 250, 226-238.

[17] Matsuo, H. (2015). Implications of the Tohoku earthquake for Toyota's coordination mechanism: Supply chain disruption of automotive semiconductors. Int. J. Production Economics 161, 217-227. 


\section{Biographies}

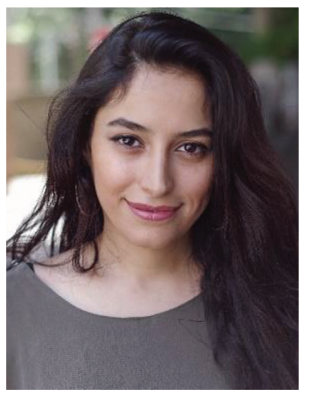

Zohreh Khojasteh-Ghamari received the B.Sc. in Information Technology (IT) Engineering from Tabriz, Iran in 2009. She received MS in Computer Science from Ca' Foscari University of Venice, Italy in 2014. Currently, she is a Ph.D. candidate in graduate school of green science and engineering, Sophia University, Tokyo, Japan.

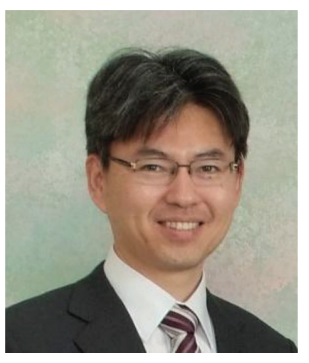

Takashi Irohara received the B.E., M.E., and Doctor of Engineering degrees from Waseda University, Japan, in 1993, 1995, and 1998, respectively. Since 2010, he has been working as a professor at the Department of Information and Communication Sciences, Faculty of Science and Technology, Sophia University, Japan. He has published over 60 reviewed journal papers in the area of facility logistics (order picking, inbound/outbound truck scheduling in the warehouse, facility layout problem, material handling), supply chain management (inventory control, transportation, and vehicle routing problem), production scheduling and humanitarian relief logistics. He served as a board member of Japan Industrial Management Association, Japanese Material Handling Society and APIEMS (Asia Pacific Industrial Engineering and Management Systems Conference). 
